\title{
Three-dimensional investigation of recrystallization nucleation in a particle-containing
} Al alloy

Zhang, Yonghao; Juul Jensen, Dorte; Zhang, Yubin; Fengxiang, Lin; Zhang, Zhiqing; Liu, Qing

\section{Published in:}

Scripta Materialia

Link to article, DOI:

10.1016/j.scriptamat.2012.05.006

Publication date:

2012

Link back to DTU Orbit

Citation $(A P A)$ :

Zhang, Y., Juul Jensen, D., Zhang, Y., Fengxiang, L., Zhang, Z., \& Liu, Q. (2012). Three-dimensional investigation of recrystallization nucleation in a particle-containing Al alloy. Scripta Materialia, 67(4), 320-323. https://doi.org/10.1016/i.scriptamat.2012.05.006

\section{General rights}

Copyright and moral rights for the publications made accessible in the public portal are retained by the authors and/or other copyright owners and it is a condition of accessing publications that users recognise and abide by the legal requirements associated with these rights.

- Users may download and print one copy of any publication from the public portal for the purpose of private study or research.

- You may not further distribute the material or use it for any profit-making activity or commercial gain

- You may freely distribute the URL identifying the publication in the public portal 


\section{Elsevier Editorial System(tm) for Scripta Materialia Manuscript Draft}

Manuscript Number:

Title: 3D investigation of recrystallization nucleation in a particle-containing Al alloy

Article Type: Regular Article

Keywords: Aluminum; Cluster/Band of particles; Dispersoid; Serial sectioning; Particle stimulated nucleation

Corresponding Author: Dr.Techn. Dorte Juul Jensen,

Corresponding Author's Institution: Risoe DTU

First Author: Yonghao Zhang

Order of Authors: Yonghao Zhang; Dorte Juul Jensen; Yubin Zhang, Ph. d; Fengxiang Lin; Zhiqing Zhang, Ph. D; Qing Liu, Ph. D

Abstract: Effects of an inhomogeneous distribution of second-phase particles on nucleation of recrystallization in a particle-containing aluminum alloy are investigated by 3D serial sectioning. Clusters and bands of big intermetallic particles are the dominating nucleation sites, but also other sites are active. Effects of nucleation sites and the inhomogeneous particle distribution on the orientation and size of the nuclei are investigated and their relationships are discussed.

Suggested Reviewers: Knut Marthinsen

Professor, Department of Materials Science and Engineering, Norwegian University of Science knut.marthinsen@material.ntnu.no

George Spanos

Materials Science\&Technology Division, Naval Research Laboratory

george.spanos@nrl.navy.mil

Anthony Rollett

Department of materials science \& engineering, Carnegie Mellon University

rollett@andrew.cmu.edu

Brian John Duggan

Dept Mech Engn, Univ Hong Kong

bjduggan@hkucc.hku.hk 
Dear Editor,

This is a resubmission of manuscript SMM-11-2429 which was handled by Editor H. Bhadeshia.

Dear Harry Bhadeshia,

Following our email conversation on our precious submission SMM-11-2429 in which the referee agreed that the $3 \mathrm{D}$ analysis were needed to address the topic we investigate, but said that the experimental data were poorly analyzed. We have followed the suggestions from the referee.

We have plotted the orientations of all the nuclei in an ODF and clearly marked the orientation ranges which we consider in our analysis. This is presented as a new figure (Fig. 4a).

We have also plotted the sizes of the nuclei in specific deformed matrices together with the calculated average values including error bars in a new figure (Fig. 4b). This figure clearly shows the large scatter in sizes but also the significant differences between the average sizes in the different matrix classes.

To further add value to the manuscript we have now also done the nucleation site analysis in $2 \mathrm{D}$ by looking at the individual $2 \mathrm{D}$ sections of the $3 \mathrm{D}$ volume independently. The results are included and very clearly demonstrates the errors introduced if only 2D data have been considered.

Finally we have tried to sharpen the text to make our results and interpretations clearer. All the new text is highlighted in yellow in the manuscript and the new figures are Figure $4 \mathrm{a}$ and $4 \mathrm{~b}$.

We very much hope our manuscript is now acceptable for publication in Scripta Materialia.

Sincerely yours

Dorte Juul Jensen 
3D investigation of recrystallization nucleation in a

particle-containing Al alloy

\author{
Yonghao Zhang, ${ }^{\mathrm{a}}$ Dorte Juul Jensen, ${ }^{\mathrm{b}, *}$ Yubin Zhang, ${ }^{\mathrm{b}}$ Fengxiang Lin, ${ }^{\mathrm{b}}$ Zhiqing \\ Zhang $^{\mathrm{a}}$ and Qing Liu ${ }^{\mathrm{a}}$ \\ ${ }^{a}$ College of Materials Science and Engineering, Chongqing University, Chongqing 400030, \\ People's Republic of China \\ ${ }^{\mathrm{b}}$ Danish-Chinese Center for Nanometals, Materials Science Division, Department of Wind \\ Energy, Technical University of Denmark, DK-4000 Roskilde, Denmark
}

\begin{abstract}
Effects of an inhomogeneous distribution of second-phase particles on nucleation of recrystallization in a particle-containing aluminum alloy are investigated by $3 \mathrm{D}$ serial sectioning. Clusters and bands of big intermetallic particles are the dominating nucleation sites, but also other sites are active. Effects of nucleation sites and the inhomogeneous particle distribution on the orientation and size of the nuclei are investigated and their relationships are discussed.
\end{abstract}

Keywords: Aluminum; Cluster/Band of particles; Dispersoid; Serial sectioning; Particle stimulated nucleation

It is widely accepted that particles are of outmost importance in recrystallization of alloys containing a large number of second-phase particles [1-7]. Generally, large non-deformable particles promote recrystallization by stimulating nucleation (Particle Stimulated Nucleation, PSN) while closely-spaced fine ones inhibit this process by pinning grain boundaries (Zener Pinning) [3, 8]. 3xxx series aluminum alloys such as 3004 and 3104 have been intensively studied because of their commercial significance in the manufacture of rigid containers (cans). Large Al-Fe-Mn-Si constituent particles clearly promote recrystallization after hot rolling. Fine $(<<1$ micron) dispersoids formed during homogenization also play a critical role in recrystallization kinetics. While the general impacts of these particles are well-established, it has been difficult to develop accurate predictive models for grain structure and texture after hot deformation. A main problem is that constituent and dispersoid particles may be inhomogeneously distributed due to micro-segregation resulting from the ingot casting process.

The present study focuses on the effects of non-uniformly distributed particles and dispersoids. Most of the former studies on PSN were carried out by 2D methods whereby key information may be lost. To the knowledge of the authors only one paper has been published containing direct 3D information on the correlation between large second-phase particles and nuclei [9]. In the present study a 3D serial sectioning

\footnotetext{
"Corresponding author. E-mail: doje@ risoe.dtu.dk
} 
method combined with Electron Channeling Contrast (ECC) and Electron Backscattered Diffraction (EBSD) are employed to reveal the relationship between nuclei and second-phase particles.

A commercial DC-cast AA3104 aluminium alloy (chemical composition in wt.\%: Al-0.9Mn-1.18Mg-0.41Fe-0.22Si-0.18Cu) was used in this work. A large number of big $\mathrm{Al}_{6}(\mathrm{Fe}, \mathrm{Mn}) / \mathrm{Al}_{12}(\mathrm{FeMn})_{3} \mathrm{Si}$ intermetallic particles were formed during casting. The starting material was heat treated at $530{ }^{\circ} \mathrm{C}$ for 10 hours and then air cooled. After the heat treatment, two types of Al-Mn-Si dispersoid with sizes from tens of nanometers (small spot-like dispersoids) to $3 \mu \mathrm{m}$ (large rod-like dispersoids) precipitated. As sketched in Figure 1a, the structure is characterized by big intermetallic particles at the grain boundaries, zones almost free of precipitates (Precipitate Free Zones, PFZs, marked A) and zones with a low density of the large rod-like dispersoids (marked B) as well as zones with a somewhat higher density of small spot-like dispersoids (marked C). Very limited further precipitation is expected during later annealing since supersaturated elements were well released during the heat treatment at $530{ }^{\circ} \mathrm{C}$, thus the influence of concurrent precipitation with nucleation can be ignored.

The material was then cold rolled to a reduction of $80 \%$ in thickness. After rolling an inhomogeneous distribution of big intermetallic particles was produced with clusters/bands of particles formed mainly along the rolling direction (RD), as sketched in Figure 1b. The width of the particle clusters/bands along the normal direction (ND) varies from 10-40 $\mu \mathrm{m}$. The zones apparently free of precipitates, with large rod-like dispersoids and small spot-like dispersoids were of course also compressed along ND (Fig. 1b). The zones with particles of different types are fairly large and easy to distinguish and the material is thus, besides being of commercial interest, ideal for studies of combined effects of large and small particles on nucleation of recrystallization. To initiate recrystallization the material was finally annealed at 300 ${ }^{\circ} \mathrm{C}$ for $1 \mathrm{~h}$.

Serial sectioning was performed with a Logitech PM5 precision lapping and polishing machine using a $1 \mu \mathrm{m}$ grit diamond suspension. Two samples were cut out and permanently mounted in a tailor made sample holder, one sample was for the characterization, and the other one was used to determine the depth removed in the sectioning steps by Vickers hardness indents. For further experimental details see [10]. ECC images and EBSD scans were made in a Zeiss Supra 35 thermal field emission gun scanning electron microscopy (SEM), the step size of the EBSD scans was $1 \mu \mathrm{m}$. An area of $510 \mu \mathrm{m}$ by $340 \mu \mathrm{m}$ was characterized with ECC and EBSD in each section and a total of 17 sections with a separation of about $2 \mu \mathrm{m}$ were studied (considering that the size of some particles and nuclei are very small, the sectioning steps was controlled to be as small as possible). The ECC image and the corresponding EBSD map from each section need to be matched after characterization, for details of the matching see supplementary material. The 3D microstructure was reconstructed from the $2 \mathrm{D}$ section images by image analysis software Reconstruct [11].

By combining ECC and EBSD, both particles and nuclei could be identified [12]. 
In the present study, particles with a size larger than $3 \mu \mathrm{m}$ are defined as big particles, smaller ones are defined as dispersoids. If no neighboring big particle is found beside one big particle within the range of its own size, we call it a 'single big particle', otherwise it will be considered as part of a big particle cluster/band. Nuclei are identified as being partly or fully surrounded by a high angle boundary (more than $15^{\circ}$ ), to be larger than $3 \mu \mathrm{m}$ and with interior misorientations below $2^{\circ}$.

An example of the observations is given in Figure 2. Figure 2a shows the EBSD map of section 5. Nuclei with different orientations can easily be distinguished. Figure $2 \mathrm{~b}$ shows the ECC image of the same area and the particles and some of the nuclei are clearly visible. After comparing Figure $2 \mathrm{a}$ and $2 \mathrm{~b}$ it is obvious that a large number of nuclei of varying orientations locate at big particle clusters/bands and thus also form clusters following the particle clusters. To get the full 3D picture of the distribution of particles of the various types and the nuclei, the 17 sections are stacked and considered together. In Figure 3a-c, sketches of the particles and nuclei in the same area from two neighboring sections (\#8 and 9) and one further away (\#14) are shown. Figure $3 \mathrm{~d}$ and $3 \mathrm{e}$ shows the full 3D reconstruction highlighting the big particles (Fig. 3d) and the nuclei plus big particles (Fig. 3e).

Within the whole inspected volume, a total of 2423 nuclei has been found, and their orientations and positions have been registered. Four types of nucleation sites are observed: single big particles, clusters/bands of big particles, large dispersoids and regions without particles or dispersoids. The results are shown in Table 1. The table shows that nearly $90 \%$ of the nuclei are found at clusters/bands of big particles. This is not surprising because large deformation heterogeneities form near big particles during rolling [1-2]. When clusters of particles are present, the inhomogeneities are expected to become even more severe. Also single big particles are observed to be good nucleation sites, $2.8 \%$ of the nuclei are found near these particles. Actually all single big particles and clusters/bands of big particles are observed to have stimulated nuclei. It should be noticed that large dispersoids may also act as nucleation sites. In this investigation, about $5 \%$ of the nuclei develop at big rod-like dispersoids which have sizes within the range from $0.5 \mu \mathrm{m}$ to $3 \mu \mathrm{m}$. This range is more or less above the critical diameter for PSN (about $2 \mu \mathrm{m}$ ) after rolling to $80 \%$ [2]. Although many particles are present in the material, they are not the only sources for nucleation, 2.8\% of the nuclei are found with no particles or large dispersoids next to them. (It should be pointed out that this fraction is likely to be an underestimate since some of the nuclei may have nucleated away from particles or large dispersoids but grown to become near them. These nuclei would thus with the present analysis be counted as part of one of the first 3 groups. )

Figure 3 illustrates the need of using the 3D method. The large nuclei and big particles (clusters/bands) extend over several sections along the transverse direction (TD), which easily lead to misinterpretations in 2D. For the present data, 2D inspections of the sections instead of the full 3D analysis leads to quite different results, for example only $74.3 \%$ of the nuclei would in 2D have been classified as near big particle clusters/bands and $13.1 \%$ would have been identified as nucleated away from particles or large dispersoids (compare to Table 1). 
The orientations of the nuclei are also known and they are divided into 3 groups according to their orientations as Cube (within $15^{\circ}$ of $\{001\}<100>$ ), Rolling (within $25^{\circ}$ of $\mathrm{S}\{123\}<634>$, Copper $\{112\}<111>$ and Brass $\{011\}<211>$ ) and Random (just everything else). The wider orientation range for the rolling component is chosen to represent well the observed width of the rolling components in the Orientation Distribution Function (ODF), see Figure 4a. With this classification 2.6\%, 52.9\% and $44.5 \%$ of the nuclei have cube, rolling and random orientations, respectively.

Out of the 2230 nuclei at single big particles or clusters/bands of big particles, $52.9 \%$ are with rolling and $44.3 \%$ with random orientations. The origin of formation of nuclei with these orientations has been discussed in [13]. In the present investigation also many cube nuclei are observed at clusters/bands of big particles (see Table 1). One may speculate if cube nuclei have grown from other areas, but this is not very likely as few cube nuclei are seen in the 'None' group and the 3D cube nuclei size on average is $7.9 \mu \mathrm{m}$ whereas rolling and random are larger, $10.5 \mu \mathrm{m}$ and $11.3 \mu \mathrm{m}$, respectively. It should be noted that if a nucleus extends through the whole inspected volume, e.g. if it is larger than $34 \mu \mathrm{m}$ along TD, it is reported as $34 \mu \mathrm{m}$ and if it extends in one direction only the size is reported as the parts which are seen. This procedure is not expected to have significant effect on the ratio between sizes of nuclei with different orientations. Hence cube nuclei also appear to form near the big particles and particle clusters/bands.

The nuclei are observed to have a wide size distribution (see Fig. 3). This wide distribution does not relate to orientations only but also the deformed matrix. Here we analyze 3 types of matrices: precipitate free zones (PFZs), zones with large rod dispersoids and zones with small dispersoids. The sizes of nuclei within these 3 types of matrices are plotted in Figure 4b. The figure shows that nuclei within zones of small spot dispersoids on average are smaller than those in PFZs and zones with large rod dispersoids. This is expected due to pinning effects. The figure also shows that nuclei within zones of large rod dispersoids are much larger than those within PFZs. This may relate to the spatial distribution of the 3 types of matrices. As shown in Figure 1b, PFZs are generally observed next to big particle clusters/bands which stimulate many nuclei. Zones with large rod dispersoids are away from the clusters/bands of big particles. Therefore fewer nuclei develop here. This gives part of the explanation. Some nuclei which have formed at the big particle clusters/bands may grow to reach the zones with large rod dispersoids. As shown in Figure 1b, this generally involves growth through a zone with small spot dispersoids - i.e. slow growth. Therefore it is expected that as soon as the first (or a few) of these slow growing nuclei reaches a zone with large dispersoids it will speed up significantly and quickly consume large parts of the zone, and thus 'blocking' the way for any neighboring nuclei reaching this faster growth zone later. Consequently the size of the nuclei observed in zones with large rod dispersoids is to a large extend determined by the size of those zones whereas the nuclei in PFZs and zones with fine spot dispersoids have sizes determined by the nucleation density at the big particle clusters/bands, as well as growth rates in the respective zone.

The present investigation has demonstrated the need for full 3D characterization 
when nucleation sites have to be identified. It has confirmed that clusters/bands of big particles are very powerful nucleation sites stimulating $90 \%$ of the nuclei predominantly of rolling and random orientations but also cube nuclei may form here. A large size variation of nuclei is observed which at this stage of recrystallization does not relate only to orientation effects but to a large extend is determined by the inhomogeneous distribution of dispersoids in the deformed matrix.

The authors gratefully acknowledge support from the National Natural Science Foundation of China (Grant No. 50901092) and from the Danish National Research Foundation and the National Natural Science Foundation of China (Grant No. 50911130230) for the Danish-Chinese Center for Nanometals, within which this work was performed. The authors also thank Prof. Brian Ralph and Dr. Robert E. Sanders for helpful comments and Mr. Steen Bang for making the sample holder.

[1] W.C. Leslie, J.T. Michalak, F.W. Aul, Iron and its Dilute Solid Solutions, Interscience, New York, 1963.

[2] F.J. Humphreys, Acta Metall., 25 (1977) 1323-1344.

[3] R.D. Doherty, D.A. Hughes, F.J. Humphreys, J.J. Jonas, D. Juul Jensen, M.E. Kassner, W.E. King, T.R. McNelley, H.J. McQueen, A.D. Rollett, Mater. Sci. Eng. A, 238 (1997) 219-274.

[4] F.J. Humphreys, D. Juul Jensen, in: N. Hansen, D. Juul Jensen, T. Leffers, B. Ralph (Eds.) 7th Risø Int. Symp. on Metallurgy and Materials Science, Ris $\varnothing$ National Lab., Roskilde, Denmark, 1986, pp. 93-106.

[5] F.J. Humphreys, Acta Mater., 45 (1997) 4231-4240.

[6] F.J. Humphreys, Scripta Mater., 43 (2000) 591-596.

[7] O. Daaland, E. Nes, Acta Mater., 44 (1996) 1413-1435.

[8] C.S. Smith, Trans. Metal. Soc. A.I.M.E., 175 (1948) 15-51.

[9] H. Weiland, T.N. Rouns, J. Liu, Z. Metallkd., 85 (1994) 592-597.

[10] F.X. Lin, A. Godfrey, D. Juul Jensen, G. Winther, Mater. Charact., 61 (2010) 1203-1210.

[11] J.C. Fiala, J. Microsc., 218 (2005) 52-61.

[12] Y.H. Zhang, D. Juul Jensen, Q. Liu, to be published.

[13] R. Ørsund, E. Nes, Scripta Metall., 22 (1988) 671-676. 
Table 1. Number of nuclei with cube, rolling and random orientations at specific nucleation sites ('None' - regions without particles or dispersoids)

Figure 1. Distribution of second phase particles: (a) after heat treatment at $530{ }^{\circ} \mathrm{C}$ for 10 hours, the structure is characterized by big intermetallic particles at the grain boundaries, zones of PFZs (marked A) and zones with large rod dispersoids (marked B) as well as zones with small spot dispersoids (marked C), (b) after cold rolling, the big intermetallic particles are broken up into clusters/bands. Note that dispersoids are drawn larger than their real size in order to be seen clearly.

Figure 2. (a) EBSD map of section 5 showing the distribution of orientations in the microstructure with different colors (red-cube, yellow-rolling), (b) ECC image of the same section showing the distribution of clusters/bands of big intermetallic particles.

Figure 3. (a)-(c) Sketches of the same area in section 8, 9 and 14. The solid black areas represent big intermetallic particles and areas surrounded by black lines represent the nuclei. Note that nuclei nI, nII and nuclei cluster nIII would have been wrongly classified as nuclei away from big particles if only one section was characterized, (d) 3D reconstruction of big intermetallic particles within the area of (a)-(c) but now using all 17 sections, most of the particles align in bands/clusters, (e) 3D reconstruction of both big intermetallic particles and nuclei (totally 368 nuclei), most of the nuclei are next to big particles and align in bands/clusters, too. Nuclei in regions $\mathrm{R} 1$ and $\mathrm{R} 2$ are obvious larger than in other regions.

Figure 4. (a) ODF which shows the orientations of all nuclei within the whole inspected volume, black broken line areas show cube and full line areas show rolling orientations, (b) sizes of nuclei within zones with large dispersoids, PFZs and zones with small dispersoids. 

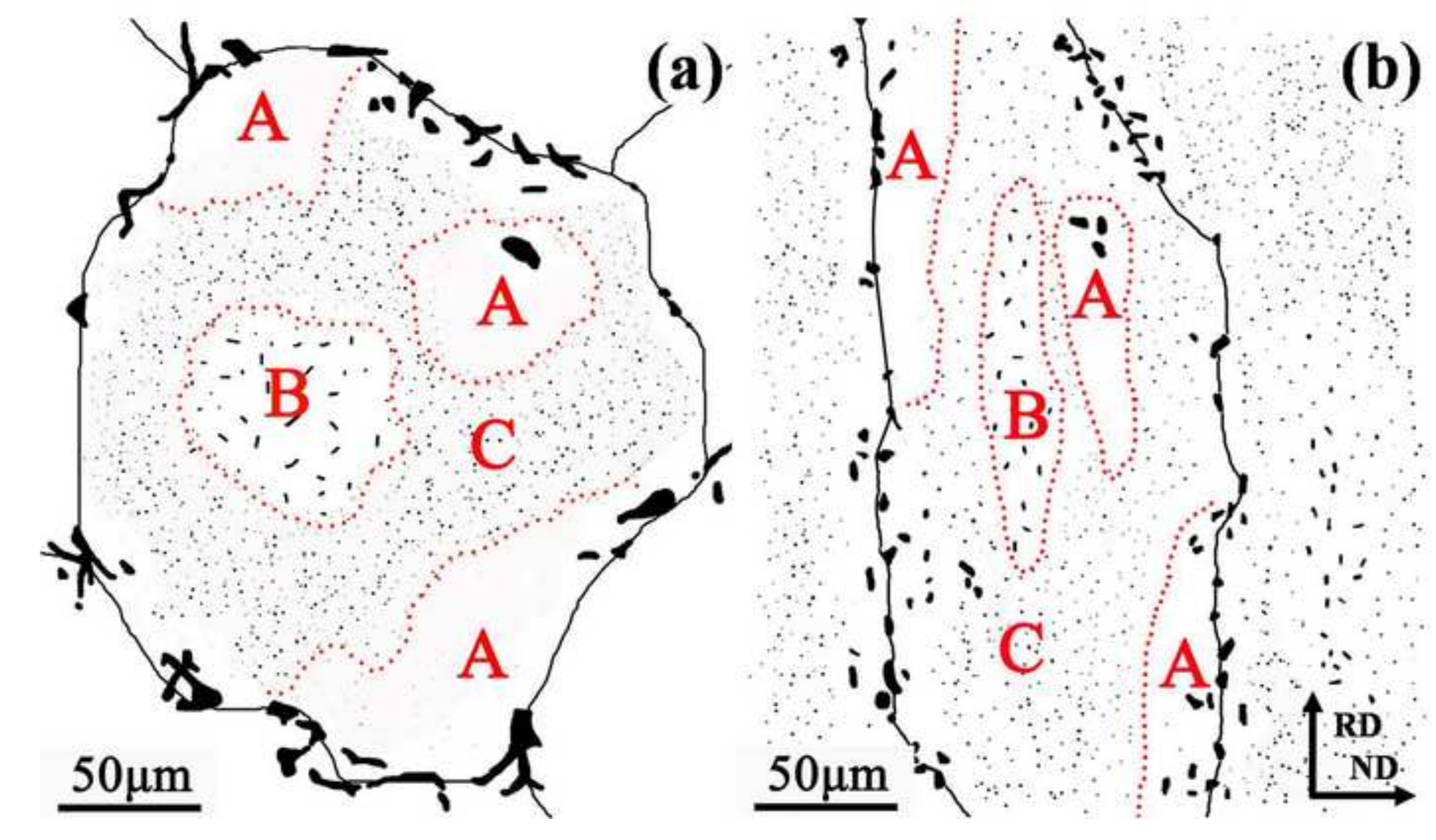

$50 \mu \mathrm{m} i$ 

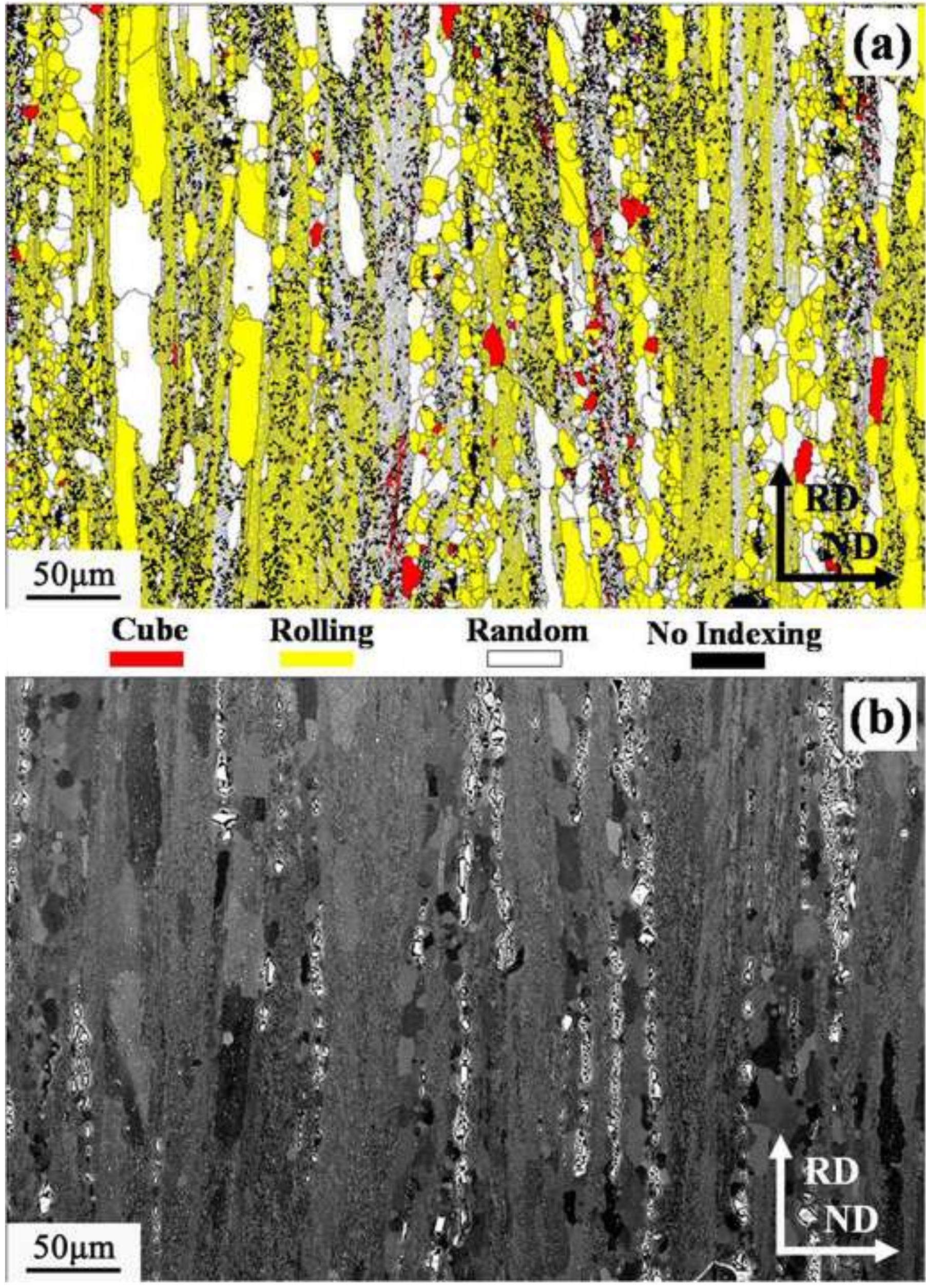


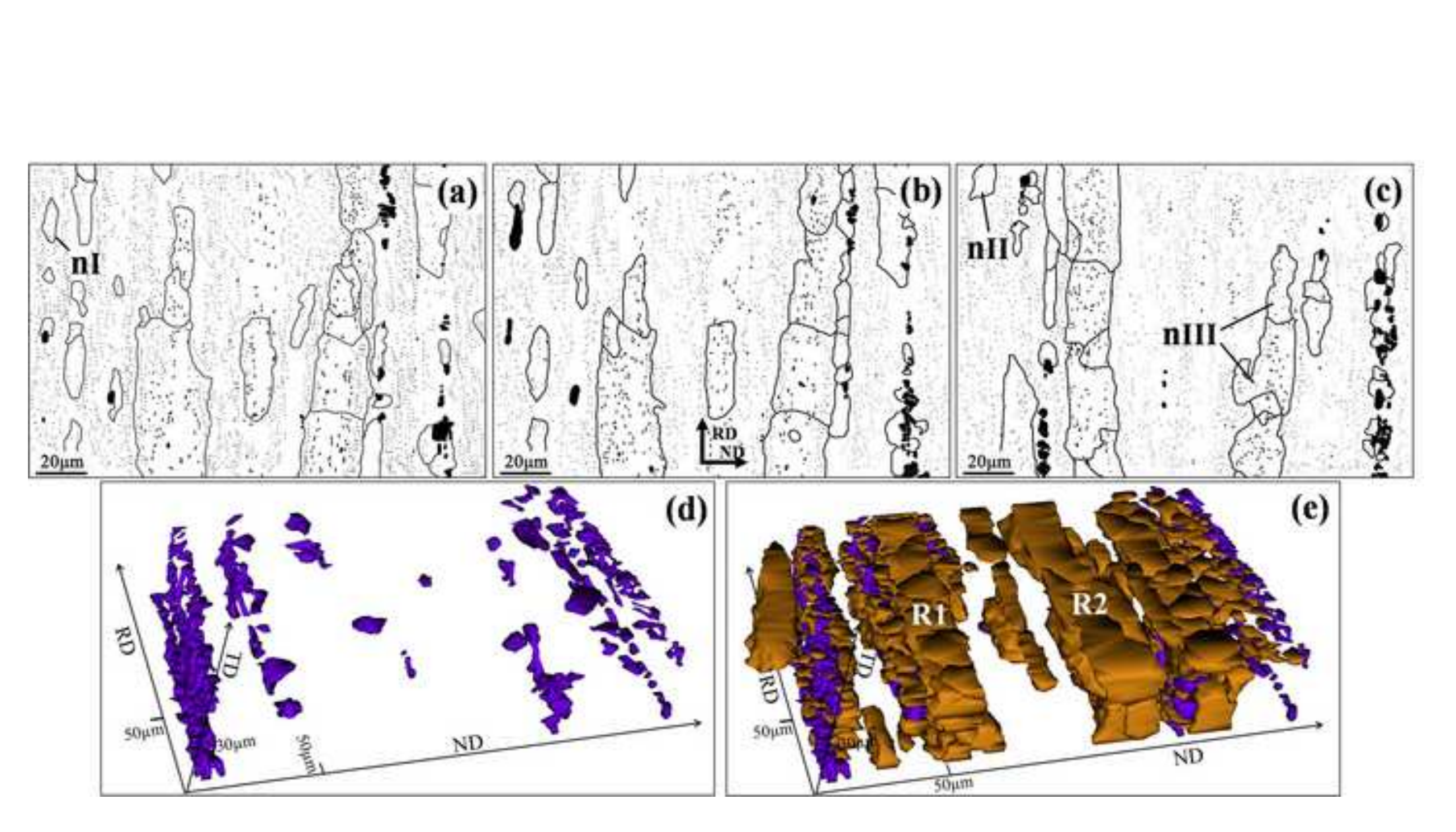

\footnotetext{
.
}

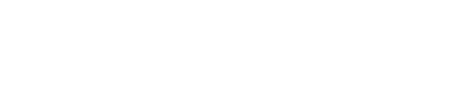

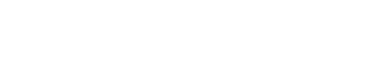




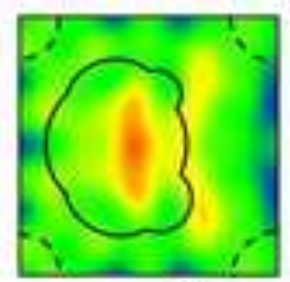

$\Phi_{2}=0^{\prime \prime}$

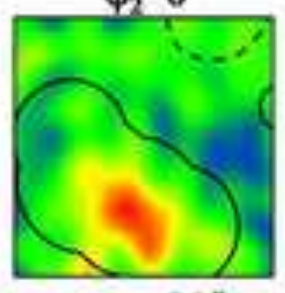

$\varphi_{2}=20^{\prime \prime}$

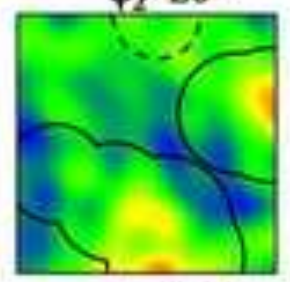

$\varphi_{2}=40^{\circ}$
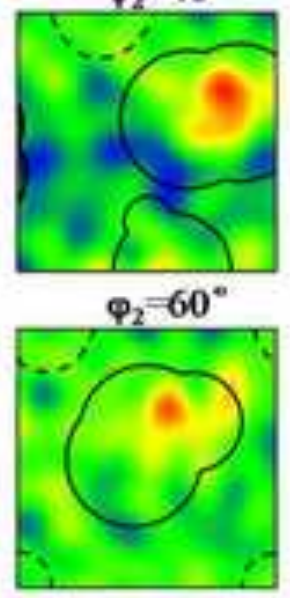

$\varphi_{2}=80^{\circ}$

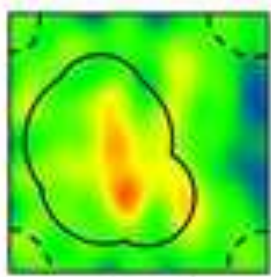

$s_{2}=5^{\circ}$

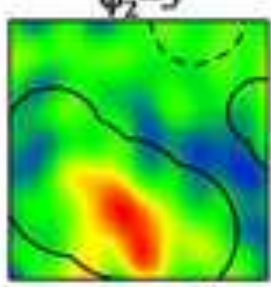

$\varphi_{2}=25^{\prime \prime}$

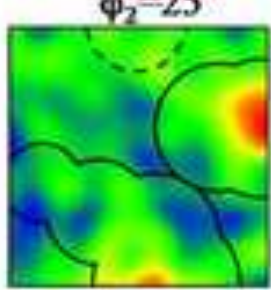

$\phi_{2}=45^{\circ}$

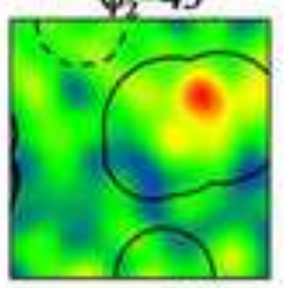

$\varphi_{2}=65^{\circ}$

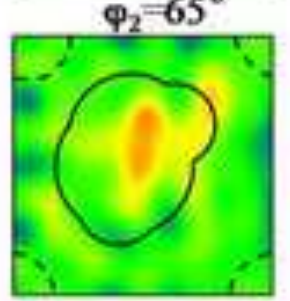

$\varphi_{2}=85^{\prime \prime}$

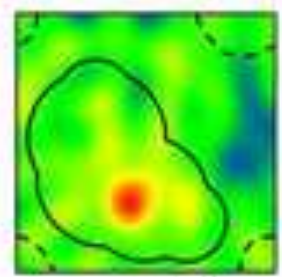

$\varphi_{2}=10^{\circ}$

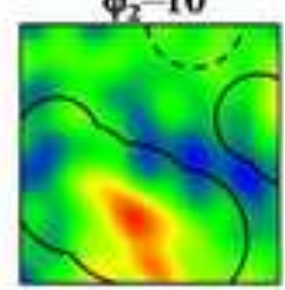

$\varphi_{2}=30^{\circ}$

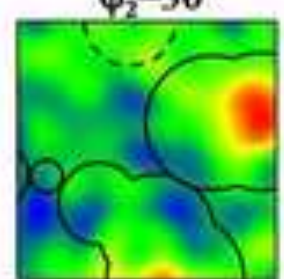

$B_{2}=50^{\circ}$

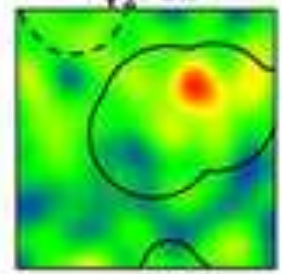

$\varphi_{2}=70^{\circ}$

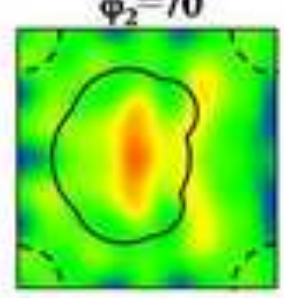

$\Phi_{2}=90^{\circ}$

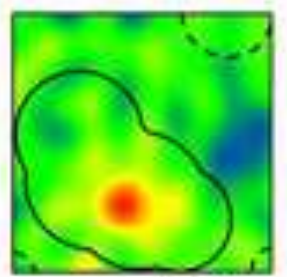

(a)

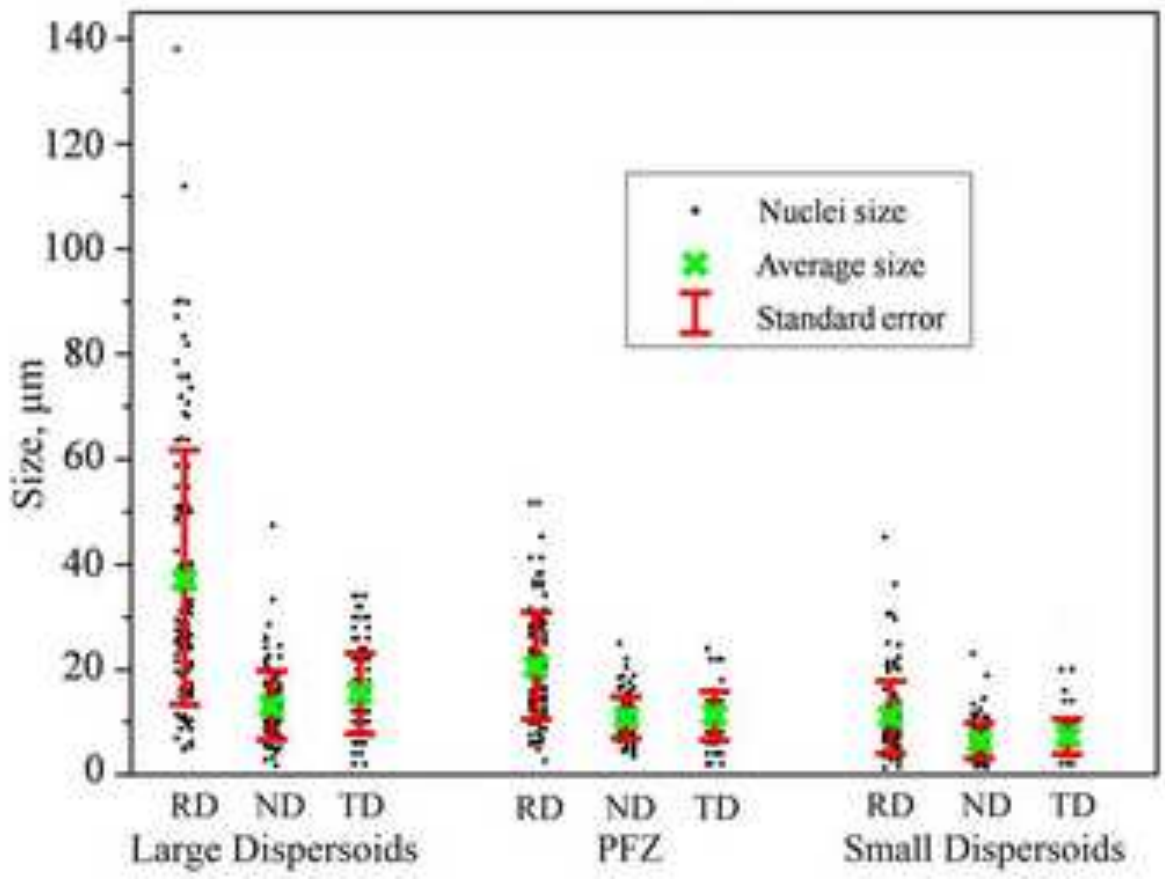

(b) 
Table 1. Number of nuclei with cube, rolling and random orientations at specific nucleation sites ('None' - regions without particles or dispersoids)

\begin{tabular}{cccccc}
\hline Site & $\begin{array}{c}\text { Single big } \\
\text { particles }\end{array}$ & $\begin{array}{c}\text { Clusters/Bands of big } \\
\text { particles }\end{array}$ & Large dispersoids & None & Total \\
\hline Crientation & 1 & 61 & 1 & 64 & 1 \\
Rolling & 34 & 1146 & 66 & 58 & 36 \\
Random & 32 & $2163(89.2 \%)$ & $125(5.2 \%)$ & $68(2.8 \%)$ & 1077 \\
Total & $67(2.8 \%)$ & & & & 2423 \\
\hline
\end{tabular}


Supplementary Material
Click here to download S

Click here to download Supplementary Material: Matching Procedure_2011.12.06.avi

ck here to download Supplementary Material: Matching Procedure_2011.12.06.avi

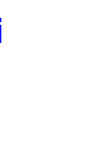

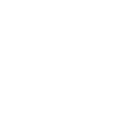

(1)

(1)

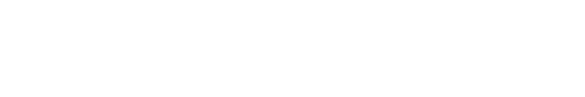


Supplementary Material
Click here to download Supplementary Material: Supplementary material_2011.12.05.doc

Supplementary Material
Click here to download Supplementary Material: Supplementary material_2011.12.05.doc

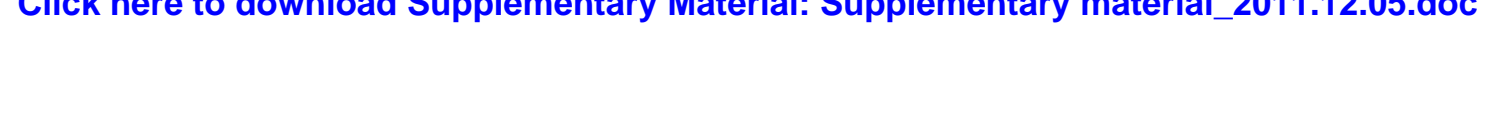

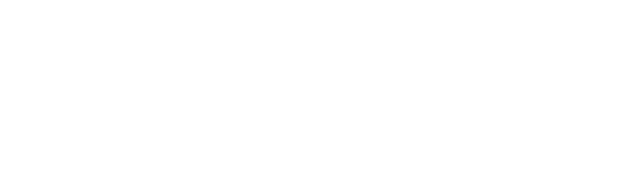

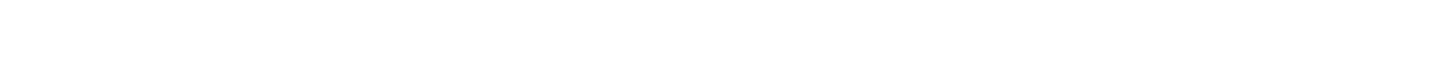

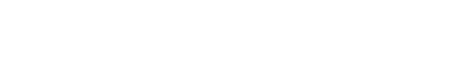

